\title{
Teaching Grammar: The Use Of The English Auxiliary "BE" Present Tense Verb Among Malaysian Form 4 And Form5 Students
}

\author{
Joanna Jishvithaa.M \\ Faculty of Educational Studies, University Putra Malaysia, Malaysia \\ Tabitha.M \\ Faculty of Educational Studies, University Putra Malaysia, Malaysia \\ Seyed Ali Rezvani Kalajahi (corresponding author) \\ Faculty of Educational Studies, University Putra Malaysia, Malaysia \\ E-mail: ali.rezvani85@gmail.com
}

Doi:10.7575/aiac.alls.v.4n.2p.152

URL: http://dx.doi.org/10.7575/aiac.alls.v.4n.2p.152
Received: 02/04/2013

Accepted: 04/06/2013

\begin{abstract}
This research paper aims to explore the usage of the English Auxiliary "Be" Present Tense Verb, using corpus based method among Malaysian form 4 and form 5 students. This study is conducted by identifying and classifying the types of errors in the Auxiliary "Be" Present Tense verb in students" compositions from the MCSAW corpus developed by (Mukundan\&RezvaniKalajahi, 2013). 273 Form 5 sample essays and 295 Form 4 sample essays were taken from four different national schools where the schools were from four different states. The errors made in the written usage of the English Auxiliary "Be" Present Tense verb were evaluated and analyzed using the Wordsmith software version 4 . The findings revealed that there are three types of errors which are the "Tense shift, Agreement and Misuse". The results show that there were more errors made by the form $4 \mathrm{~s}$ compared to the form $5 \mathrm{~s}$ even though the difference of the frequencies of errors produced by both the levels were not of much difference. Therefore, the findings of this study can be used as a guide in enabling secondary school teachers to revise and be more prepared in their teaching instructions, materials and procedures. It will help teachers look into the possible remedial actions which could be taken into consideration to overcome the problems faced by Malaysian secondary school students in using the Auxiliary "Be" Present Tense verb.
\end{abstract}

Keywords: Auxiliary, Learner corpus, Frequency, Wordsmith

\section{Introduction}

Learning the English language has always been the driving force for many students as it is widely used as the "Lingua Franca" around the world. The $21^{\text {st }}$ century has emphasized the importance of the English language as being used all over the world and is spoken by nearly one out of four of the world's population. According to Crystal (1995:106), the high position of the English language in the world has mainly two explanations. First the British Empire with its colonies all over the world and second, the United States as the leader of the field of economics. English Language in Malaysia according to Solomon (1988) has had a comparatively long history. Since attaining independence in 1957, Malaysia has gone through vast changes in various fields. Malaysia has been multilingual and Malaysia has continued to practice linguistic segregation as far as individual schools are concerned, a divide-and-rule system inherited from the colonial era (Solomon, 1988). Englishis a compulsory second language (L2) in Malaysian schools. English lessons, which are conducted daily, begin at Standard one at the age of seven. Malaysian students come from different backgrounds in life and have different levels of knowledge and proficiency in the English Language. Mastering a second language for any individual can be a very complicated and difficult task, especially for those who have always been communicating with others using their first language. David and Naji (2000) and David and Nambiar (2001) pointed out that "many of urban children who use English as their First Language (L1) or dominant language at home were able to master the language well compared to the majority of children, especially those from the rural areas, who were predominantly ethnic Malay. These rural students come from English as Foreign Language (FL) settings and start school with hardly any knowledge of English"

Arshad and Hawanum (2011) illucidates that Malaysia being a multi-ethnic population uses the Malay language as the national language. Nevertheless, the other languages used by the other ethnic groups are utilized in their specific language 
medium schools (known as 'National-type schools') and communities such as Tamil by the Indians and Mandarin by the Chinese. This has resulted in the lack of opportunity to acquire the English language in a natural setting; therefore, "formal instruction in the classroom has become the main source of learning the language in a limited time. Secondary school ESL learners have only a minimum contact of approximately 5 hours per week with the language in their respective classrooms".

As English occupies the status of a L2 in the Malaysian education system in both primary and secondary schools, there is an urgency for Malaysians to be proficient in the language as mastering it is also quite an important element in the recruitment of employees' job opportunities' and also to pursue higher education. However, learning English as an L2 is not an easy task especially for those learners from the rural areas of the country. According to Brown (2000), in order to master the English language, learners have to be adequately exposed to all of the four basic skills, namely listening, speaking, reading and writing. Though Malaysian students have been learning English for several years in school, they are not being given enough opportunities to be exposed or to have adequate interactions and conversations in the language. This therefore adds to the outcome of where learners are bound to make errors and therefore contributes to the standard of English among Malaysian students declining. Not only that, they still seem to commit errors in all aspects of the language (Saadiyah\&Subramaniam, 2009).

The familiarity with the types of errors students make is important in order to prepare effective instruction and implementation in the classroom. According to Stapa\&Zahar (2010), to those who are concerned with the standard of English language learning and teaching, the errors of language learning have always been the focus especially in the knowledge of grammar. This statement has been further supported by other researchers such as Lightbown\&Spada (2006) (as cited in Muftah\&Rafic-Galea, (2013) who state that the development of the second language is shown by the errors made by learners' in language learning and the knowledge of grammar. In addition, Brown (1987) states that error was considered the result of ineffective learning of the rules of the target language in the behaviorist theory of language learning.

\section{Problem Statement}

The Malaysian education system emphasizes the importance of enquiring and mastering the English language as it is stressed to be the second language in the educational system. Even though this language has been integrated in the standard 1 educational syllabus and up to the highest level in the secondary school, the Malaysian school learners still make a lot of mistakes as they have yet to master the L2 effectively (Stapa\&Izahar,2010).

Corder (1981) claims that ESL learners are not aware of their errors and are apparently unable to correct these errors themselves. In addition to that, Muftah\&Rafic-Galea (2013) states that the knowledge of grammar, particularly tense, is the most fundamental yet challenging part for ESL learners to master properly. This is because many L1 languages do not have tenses (Lin Ying Cao, 2012; ZhuangXin, 2010; Mourssi, 2012). Therefore, in most cases learners are unaware that mastering the use of the English tenses will not help in the process of mastering the English language.

Tense could be defined as the grammatical element used in enabling to locate a situation in time which is in the form of present, past, continuous/ progressive or the future tense. Even though learning the tenses is a rather complex process, it is very much important in the English language because it tells us the general or the specific time relating to the occurrences of any verb.

This study is to look into students' mastery in using the Auxiliary "Be" Present Tense Verbs in composition writing as it is of high importance to study this matter precisely in order to discover the possible cause of why these errors are being made and therefore to investigate how the situation can be improved or utilized for useful learning. Therefore, this study will examine the following research questions below;

1. What types of auxiliary 'be' present tense verb errors are found in the argumentative essays written by Malaysian Form 4 and Form 5 students?

\section{What is the frequency of auxiliary 'be' present tense verb errors found in the argumentative}

essays written by Malaysian Form 4 and Form 5 students?

\section{The Importance of the Study}

Several studies have been conducted to identify the errors made in the usage of the English auxiliary "BE" Present Tense Verb among students from all around the world. Therefore, this study is of great importance to teachers, educators and learners in the teaching and learning of grammar skills. Not only that, it also serves as a great purpose of giving teachers some insights of the usage of this grammar element and the problems students face while using it in their compositions, thus making it a useful guide enabling secondary school teachers to revise and be more prepared in their teaching instructions, materials and procedures. In a way, this study is important as it will help teachers and educators look into the possible remedial actions. This will help to overcome the problems faced by Malaysian secondary school students in using the Auxiliary "Be" Present Tense verb. In other words, it will help teachers, language instructors or practitioners to know the source of errors and be able to devise their teaching strategies. The improvement of the teaching strategies could be made at an early stage if the sources of errors influencing the students are known thus leading to a more effective L2 teaching and learning of grammar in classrooms. 


\section{Literature Review}

Most of the current studies in error analysis investigate either the linguistic classification of errors or on the causes of errors made by students in learning English. Auxiliary "BE" Present Tense Verb is often a problem because students are often under the assumption that they have to use the same Auxiliary "BE" Present Tense Verb throughout the essay. According to Vongthieres(1974), the rigid use of the Auxiliary "BE" Present Tense Verb leads to problems and the errors occur when they use the wrong verb tense which are common grammar mistakes.

A number of studies have been conducted in the area of errors made and it has been revealed that Auxiliary "BE" Present Tense Verb form errors contributed to the highest percentage of errors that students made. Bhatia (1974) conducted an error analysis study at the University of New Delhi. The subjects were second year Bachelor of Arts students aged about 17, with Hindi as their mother tongue. They wrote a 250-word free composition for their regular class work out of which verb forms and tense sequence made up $40 \%$ of the errors.

A study found by Richards (1971) exhibits that the understanding of the "BE" form is distorted. According to him, inappropriate teaching material for the form "was" which could be interpreted as a marker of the past tense ,could also lead to errors with the verb-forms of "has/have" and "was".

Arshad\&Hawanum (2011) conducted a corpus study by using the Malaysian School Students (EMAS) corpus on the use of the auxiliary "Be" among Primary 5. The study looked into sentences from two corpus sets. The first set was a collection of oral and written language of primary 5, Form 2 and Form 4 learners in 2000 while set two was a collection which was a smaller scale version of set one of the same language tasks and educational levels in 2007. Only the primary 5 learners and the narrative essay entitled "The Happiest Day of My Life" were used from both sets. Their research revealed that the students retained the auxiliary "Be" even when it is not needed (Arshad\&Hawanum 2011).

Saadiyah and Subramaniam (2009)examined errors in a corpus of 72 essays written by 72 participants. All of them had their primary education in National schools, in which Malay was the medium of instruction. English was taught as an additional subjectwithin the school curriculum. The participants were Form Four Malay students who were studying at a secondary school in Malaysia; 37 male and 35 female. All of the 72 participants were required to write a report entitled "Cleanliness of the school canteen" within a period of 60 minutes with a minimum of 200-250 words. Markin software was utilized to analyze the errors in the essays. All of the participants had experienced approximately the same number of 10 years of the education through the primary and secondary education system. All of theparticipants come from non-English speaking background and hardly communicatedinEnglish outside the school. The result of the study shows that one of the most Auxiliary Verbs To "BE" errors were made by Chinese students because in their L1, no auxiliary Verb To "BE" is required. Wrong application of verb tense was identified when the participants did not apply the correct tense to the verb in the sentences.

The Auxiliary 'BE' Present Tense Verb is a difficult structure for second language learners to acquire. Tode (2003) provides the example of Japanesesecond language learners of English. He notes that half the grades 8 and 9 studentswho had studied English for one year and two years respectively failed to supply"BE" in obligatory contexts as well as overused it in the context of the simple present full verb. For example, "He is like music" (p. 15). The underuse as well as overuse of the "BE" form is not surprising.

These reasons to the occurrence of errors call for a further examination of ourteaching materials in a second language classroom. As teachers, we cannot assume that learners will photographically reproduce the language structures we taught them. Thiskind of reproduction may lead to deviants in their sentence.

NorwatiRoslim and Mukundan (2011 as cited in Menon, 2009), that there are not many corpora on the English language used in Malaysia which are also not easily available to public viewers. Studies on corpora show that only four notable corpora were to be found developed from a few different universities. They are the English language of Malaysian School Students (EMAS) compiled by ArshadAbdSamad(2002) from University Putra Malaysia, the textbook corpus of the Form One to Form Five Malaysian English Language textbooks written compiled by Mukundan and Anealka Aziz (2007), also from University Putra Malaysia, Malaysian Corpus of Learner English (MACLE) developed by Knowles and Zuraidah (2004) from University Malaya, and lastly the Corpus of Malaysian English Language (COMEL) who was developed by NorwatiRoslimandMukundan (2011).

In 2013, a new corpus was created known as the Malaysian Corpus of Students' Argumentative Writing (MCSAW) by MukundanandRezvaniKalajahi(2013). It was created for this research and for other number of corpora research produced by student researchers from the University Putra Malaysia under the guidance of the corpus expert, Professor J. Mukundan and his assistant, A. Rezvani.

\section{Method}

\subsection{Population and Sampling}

This MCSAW corpus-based study investigates the ways how the auxiliary "Be" Present Tense Verbs are used in the compositions of the secondary form 4 and 5 students. The population for this study was data of corpus collected from the secondary Form 4 and 5 students from four different schools; where each school was from a different state.An argumentative essay entitled "The Advantages and Disadvantages of Facebook" with approximately 250 words was carried out in schools under the supervision of the students' own school teachers. 


\subsection{Instruments}

This study was required to identify the frequencies of errors and the types of Auxiliary 'BE' Present Tense Verb that are produced in these essays. Therefore, the Auxiliary 'BE' Present Tense Verb errors were identified and categorized using Wordsmith Tools version 4.0 and the concordance search consisted of "is" and "are". The concordance search enables the search through the discourse data for all the instance of a given word and then the surrounding context for each instance is found. The sentences were manually analyzed. Using corpus such as this to identify and investigate the problemsof ESL learners enables researchers to obtain authentic and genuine data for valid investigations of learners' errors.

\subsection{Research Limitation}

Although this research was carefully prepared, there are limitations and shortcomings. First of all, the research was confined to only four states therefore the results cannot be generalized to all students in Malaysia. Secondly, the research was limited to only the Auxiliary "BE" Present Tense Verb. Therefore, it is not an indication on students' usage of the Auxiliary "BE" past tense verb or other grammatical items. Lastly, the research was confined only to Form 4 and Form 5 students. Therefore, the results cannot be generalized to other learners of different age groups.

\section{Results and Findings}

In this section, the findings are specifically presented and discussed. The analysis answers the following research questions:

1. What types of auxiliary 'be' present tense verb errors are found in the argumentative essays written by Malaysian Form 4 and Form 5 students?

2. What is the frequency of auxiliary 'be' present tense verb errors found in the argumentative essays written by Malaysian Form 4 and Form 5 students?

\subsection{Frequency of Auxiliary 'Be' Present Tense Verb used}

Form 4 and Form 5 Malaysian ESL students, used the Auxiliary 'Be' Present Tense Verb in their compositions of the argumentative essay entitled "The Advantages and Disadvantages of Facebook." Table 1 displays the frequency of the Auxiliary 'Be' Present Tense Verb used in their argumentative essay.

Table 1. Frequency of auxiliary 'be' present tense verb used in argumentative essay entitled "The Advantages and Disadvantages of Facebook."

\begin{tabular}{ccccc}
\hline $\begin{array}{c}\text { Auxiliary } \\
\text { 'BE' Present Tense } \\
\text { Verb Form }\end{array}$ & Error Free & Error Laden & Error Free & Error Laden \\
\hline is & 2028 & 151 & 2100 & 119 \\
& $(93.07 \%)$ & $(6.93 \%)$ & $(94.64 \%)$ & $(5.36 \%)$ \\
are & 1095 & 77 & 928 & 45 \\
& $(93.43 \%)$ & $(6.57 \%)$ & $(95.4 \%)$ & $(4.6 \%)$ \\
\hline
\end{tabular}

Form 4 students attempted the Auxiliary "Be" Present Tense verb approximately 3351 times with 3123 (93\%) attempts being correct and $228(6.8 \%)$ being erroneous. On the other hand, there were all together 3192 attempts of the tense verb usage made by the Form 5 students in their essays with 3028 (94\%) attempts being correct and 164 (5.1\%) being incorrect. The total erroneous attempts produced by both Form 4 and Form 5 students summed up to 392 attempts which consisted of $23.46 \%$ overall. This indicates that the Form 4 and Form 5 students may still have problems understanding and using the Auxiliary "Be" Present Tense verb despite having learnt the L2 between nine to ten years.

\subsection{The overall errors types and frequency in Advantages and Disadvantages of Facebook.}

Table 2.The Types of Error and the Frequency of auxiliary 'be' present tense verb used in argumentative essay entitled "The Advantages and Disadvantages of Facebook."

\section{Frequency of Errors $\quad$ Frequency of Errors (\%)}

$\begin{array}{lllll}\text { Types of Errors } & \text { Form } 4 & \text { Form } 5 & \text { Form } 4 & \text { Form } 5\end{array}$

\begin{tabular}{lcccccccc}
\hline & Is & Are & Is & Are & Is & Are & Is & Are \\
Tense Shift & 2 & 7 & 0 & 0 & 2.19 & 9.09 & 0 & 0 \\
Agreement & 76 & 46 & 89 & 27 & 83.51 & 59.74 & 74.79 & 60 \\
Misuse & 13 & 24 & 30 & 18 & 14.28 & 31.16 & 25.21 & 40 \\
\hline Total & $\mathbf{9 1}$ & $\mathbf{7 7}$ & $\mathbf{1 1 9}$ & $\mathbf{4 5}$ & $\mathbf{1 0 0}$ & $\mathbf{1 0 0}$ & $\mathbf{1 0 0}$ & $\mathbf{1 0 0}$ \\
\hline
\end{tabular}


The essays that were collected were analyzed into data in a very precise manner, with sentence by sentence examination using Error Analysis (EA) so that the types of error for the Auxiliary "Be" Present Tense verb could be detected in detail. Referring to Table 2 above, the data shows the types of errors and the frequency of errors produced by students in their essay composition for this study. Using the MCSAW Corpus Analysis, 3 types of errors of the Auxiliary "Be" Present Tense Verb were detected namely the "Tense Shift, Agreement, and Misused". The findings above will be illustrated and be accompanied by further discussions such as below:-

\subsection{Types and Frequency of errors}

\section{Tense shift}

Tense shift is the change from one verb tense to another within a sentence or paragraph. It is usually changed from past tense to present tense or from present tense to past tense.

\section{Example:}

\section{Form 4 "are"}

There also was an opportunity for Facebook artists to promote their album. (File 866)

The accurate auxiliary 'be' is:

There is also an opportunity for Facebook artists to promote their albums.

\section{Form 4 "is"}

Facebook also was like a large community with billions of fans. (File 983)

The accurate auxiliary 'be' is:

Facebook is also like a large community with billions of fans.

\section{Form 5 "are"}

Note : There are no tense shift errors produced by students in this level.

\section{Form 5 "is"}

Note : There are no tense shift errors produced by students in this level.

Relating to the tense shift verb error produced by students, the frequency portrays that $2.19 \%$ of the overall Form 4 students produced errors in "is" and 9.09\% errors in "are". On the other hand, a percentage of $0 \%$ for both tense shift verb of Form 5 students produced this error. The construction of this error is due to the fact that the form 4 students may have overlooked the transition in time of the present and past time while constructing their essays while the Form 5 students may have mastered this verb tense properly.

\section{Agreement}

Agreement is to be understood as the verb agreeing with the singular or plural subject.

\section{Example:}

\section{Form 4 "are"}

It arehow we used it wisely. (File 225)

The accurate auxiliary 'be' is:

It $i s$ how we use it wisely.

\section{Form 4 "is"}

This is the advantages of Facebook. (File 991)

The accurate auxiliary 'be' is:

These are the advantages of Facebook.

\section{Form 5 "are"}

The disadvantage of Facebook are the privacy. (File 670)

The accurate auxiliary 'be' is:

The disadvantage of Facebook $i$ s the privacy.

\section{Form 5 "is"}

Groups and fan pages out there which is being created to abuse or violate people. (File 391)

The accurate auxiliary 'be' is:

Groups and fan pages out there whichare being createdis to abuse or violate people. 
Relating to the Agreement error produced by students, the frequency of error portrays $83.51 \%$ for "is" and $59.74 \%$ for "are" of the overall Form 4 students. On the other hand, a percentage of $74.79 \%$ for "is" and $60 \%$ for "are" are produced by form 5 students. This is because students are prone to make careless mistakes and overlook the singular and plural subjects when using the verb.

\section{Misuse}

In misuse, learners know the rules but produce something else although it is incorrect or they may have overlooked the sentence.

\section{Example:}

\section{Form 4 "are"}

It is used all over the world no matter which they are the young ones or the elder ones.

(File 1011)

\section{The accurate sentence is}

It is used all over the world for both young and the olderones.

\section{Form 4 "is"}

In Facebook these are one advantages is people advertise their product through Facebook.

(File 1000)

The accurate sentence is

In Facebook, one of the advantages is thatpeople advertise their productsthrough Facebook.

\section{Form 5 "are"}

In Facebook you can make your business are known well easily. (File 4/721)

The accurate sentence is:

In Facebook you can make your business well known easily.

\section{Form 5 "is"}

Facebook is usually is use to connect one people to another. (File 4/572)

The accurate sentence is :

Facebook is usually used to connect one person to another.

Relating to this error, the frequency indicates that $14.28 \%$ for "is" and $31.16 \%$ for "are" errors are produced overall by Form 4 students. On the other hand, a percentage of $25.21 \%$ for "is" and $40 \%$ for "are" are produced by Form 5 students. Students tend to produce a sentence by placing the auxiliary verb to "BE" even though it is unnecessary. This could be due to students' lack of understanding about when to use the auxiliary verb 'be' resulting in overuse.

\section{Conclusion and Suggestions}

The findings of this study show that Malaysian upper secondary school students still do face some difficulties in the Auxiliary 'Be' Present Tense Verb even though they did produce more correct usage than incorrect ones. However, the findings also indicate that there are some points to be taken into consideration for this study. There are three types of errors made by the students in their writing composition. They are tense shift, agreement, and the misuse of tense verb. Thus, this gives an insight to some suggestions to prevent these problems from reoccurring as much as possible. First students should be given precise feedback so that they have a better understanding in order to make changes in their writing. This would be a useful method in improving their writing skills in the future. Secondly, teachers should look into the errors made by the students and try to improvise their strategy by using constructive plans in their teaching and learning process. Teachers should also look into the possible remedial actions which could be taken into consideration to overcome the problems faced by Malaysian secondary school students in using the Auxiliary "Be" Present Tense verb and also stress more on teaching grammar in classes as it is one of the most important elements of the English language structure. Lastly, with the advancement of technology, almost everyone and anyone could surf the net regardless of age. Therefore, teachers and educators should also conduct lessons in the computer labs where they could suggest online learning, games and quizzes related to the Auxiliary "Be" Present Tense Verb English grammar which could not only be useful and interesting but could further improve their understanding and application of the grammar taught. 


\section{References}

Ahour, T., \& Mukundan, J. (2012). Errors and Variations of TESL Students' Written Description.Pertanika Journal Of Social Sciences \& Humanities, 20(1), 55.

Arshad, A.S. ,\& Hawanum, H.(-) Teaching grammar and what student errors in the use of the English auxiliary 'be' can tell us, The English Teacher, XXXIX, 164-178.

Brown, H. D. (1987). Principles of language learning and teaching. Englewood Cliffs, NJ: Prentice Hall, Inc.

Bhatia, A. T (1974). An error analysis of students' compositions.IRAL 12(4).

Corder, S.P. (1967).The significance of learners' errors. International Review of Applied Linguistics, 5/2-3, 161-169.

Corder, S. P. (1981).Error Analysis and Interlanguage. Oxford: Oxford University Press.

Crystal, D. (1995). The Cambridge Encyclopedia of the English Language. Cambridge University Press, Cambridge.

Darus, S., \& Kaladevi, S. (2009). Error Analysis of the Written English Essays of Secondary School Students in Malaysia: A Case Study. European Journal of Social Science. 8/3

Elliot, A. B. (1983). Errors in English. Singapore University Press: Singapore. Ellis, Rod. Becoming Grammatical, Website 1999-2003by Lateral Communications.

Hedström, K.E. (2001). Grammatikinlärning, in Språkboken. Skolverket, Stockholm

Khodabandeh, F. (2007). Analysis of students' errors: The case of headlines. The Asian ASP Journal, 3(1), 6-21.

Lee, J., \& Seneff, S. (2008). Correcting Misuse of Verb Forms, Columbus, Ohio, USA, June 2008. pages 174-182,

Muftah, M., \&Rafic-Galea, S. (2013). Error Analysis of Present Simple Tense in the Interlanguage of Adult Arab English Language Learners. English Language Teaching, 6(2), 146-154. doi:10.5539/elt.v6n2p146

Mukundan, J., and Aziz, A. (2009). Loading and distribution of the 2000 high frequency words in Malaysian English Language Textbooks for Form 1 to Form 5.Pertanika Journal of Social Science and Humanities, 17(92), $209-220$.

Mukundan, J., Rezvani Kalajahi, S.A. (2013). Malaysian Corpus of Students'Argumentative Writing (MCSAW).Australia, Australian International Academic Center.

Malmberg, P. (2001). Språksynenidagenkursplaner, in Språkboken.Skolverket, Stockholm

Roslim, N., \& Mukundan, J. (2011). An Overview of Corpus Linguistics Studies on Prepositions. English Language Teaching Journal: English language teaching, 4(2), 125-131

Richards, D.R. (1971). On Communicative efficiency and the treatment of error.Audio-visual language journal, 15(1).

Roselind, W, Jacqueline, S., and Kamaruzaman, J. (2009).Verb-form errors in EAP writing, 1University of Technology, MARA. Educational Research and Review, 5(1), 16-23.

Roslim, N. \&Mukundan, J. (2011). An overview of corpus linguistic studies on preposition.Canadian Center of Science and Education, English Language Teaching, 4(2), 125-131.

Samad, A., \& Hussein, H. (2010). Teaching grammar and what student errors in the use of the english auxiliary 'be' can tell us. English Teacher, 39.

Stapa, S., \& Izahar, O. (2010). Analysis of errors in subject-verb agreement among Malaysian ESL learners. 3L: Southeast Asian Journal Of English Language Studies, 16(1), 56-73.

Svartvik, J. (2001). ’Språketiframtiden”, in Språkboken.Skolverket, Stockholm

Sattari, A. (2012). An analysis of grammatical errors in Iranian students' English writings. Iranian EFL Journal, 8(2), 143157.

Tode, T. (2003). From unanalyzed chunks to rules: The learning of the Englishcopulabe by beginning Japanese learners of English. International Review of Applied Linguistics in Language Teaching, 41, 23-53. Tode, T. (2007). Durability problems with explicit instruction.

Wong, B. E. (2012). Acquisition of English Tense and Agreement Morphology by L1 Malay and L1 Chinese Speakers. 3L: The Southeast Asian Journal of English Language Studies, 18(3), 5-14. 